\title{
Efeito da aplicação de manganês no rendimento e na qualidade de sementes de soja ${ }^{(1)}$
}

\author{
Eliseu Norberto Mann(2), Pedro Milanez de Resende( ${ }^{(3)}$, Renata Silva Mann(2), \\ Janice Guedes de Carvalho ${ }^{(4)}$ e Édila Vilela de Resende Von Pinho(3)
}

\begin{abstract}
Resumo - O desequilíbrio nutricional, principalmente dos micronutrientes, tem sido um dos fatores para perdas na produção de sementes. Esses nutrientes desempenham papel em rotas bioquímicas que garantem a formação de lipídeos, proteínas e ainda contribuem na estruturação das membranas celulares. O objetivo deste trabalho foi avaliar a influência da aplicação de Mn na folha e no solo, sobre o rendimento e a qualidade de sementes de soja, cultivares Conquista e Garimpo. A qualidade das sementes foi avaliada por meio de testes de germinação, envelhecimento artificial, condutividade elétrica, índice de velocidade de emergência e pela determinação dos teores de proteína e óleo. Verificaram-se aumentos na produtividade, na germinação, no vigor e nos teores de proteína e óleo das sementes e no teor de Mn na planta, nas duas formas de aplicação do Mn, com maior grau de eficiência da aplicação na folha.
\end{abstract}

Termos para indexação: Glycine max, aplicação foliar, vigor da semente, solo, produtividade.

\section{Effect of manganese application on yield and seed quality of soybean}

\begin{abstract}
The nutritional unbalance, mainly with micronutrients, has contributed for losses in seeds yields. These nutrients are carrying out in biochemistry paths responsible for metabolism of lipids, proteins, and structure in cells membranes. The objective of this work was to evaluate the influence of Mn application (leaf or soil) on yield and seed quality of two soybean cultivars, Garimpo and Conquista. Seed quality was assessed through germination test, accelerated ageing, electrical conductivity, emergence speed, protein and oil content. The application of Mn in the soil or sprayed on the leaves increased its content in plant tissue, improved seed quality by increasing its protein and oil content as well as its germination and vigor. The Mn sprayed on the leaves was more efficient than when this nutrient was applied in the soil.
\end{abstract}

Index terms: Glycine max, foliar spray, seed vigor, soil, productivity.

\section{Introdução}

Sintomas de deficiência de Mn comumente ocorrem em situações de cultivo em solos com baixa fertilidade natural, com a utilização intensiva de técnicas agrícolas, que promovem a retirada crescente de micronutrientes, sem a reposição, e em casos onde

\footnotetext{
(1) Aceito para publicação em 23 de julho de 2002.

Extraído da dissertação de mestrado apresentada pelo primeiro autor à Universidade Federal de Lavras (Ufla), Lavras, MG.

(2) Universidade Federal de Sergipe, Dep. de Agronomia, Av. Marechal Rondon, s/ño, CEP 49100-000 São Cristóvão, SE. E-mail: eliseumann@aol.com, renatamann@hotmail.com

(3) Ufla, Dep. de Agricultura, Caixa Postal 37, CEP 37200-000 Lavras, MG. E-mail: pmrezend@ufla.br, edila@ufla.br

(4) Ufla, Dep. de Ciências do Solo. E-mail: janicegc@ufla.br
}

há aplicação excessiva de calcário, tornando o nutriente pouco solúvel. A utilização intensiva de fosfatos no solo também contribui para a baixa disponibilidade dos micronutrientes (Mascarenhas et al., 1996).

Durante a maturação da soja, condições climáticas desfavoráveis e o desequilíbrio nutricional - causado, na maioria das vezes, por recomendação errônea de doses de calcário e de adubos - afetam a obtenção de sementes com boa qualidade fisiológica (Guodong \& Jinling, 1989; Hurburg Junior et al., 1990).

A qualidade fisiológica das sementes pode ser reduzida pela deterioração decorrente de fatores climáticos associados às mudanças bioquímicas e fisiológicas, que provocam alterações na viabilidade, decréscimo na capacidade germinativa, causados pela desestruturação dos sistemas de membranas celulares, resultando num aumento da permeabilidade ce- 
lular (Carvalho, 1994). As causas fisiológicas e os fatores genéticos que afetam a viabilidade e o vigor de sementes de soja são pouco conhecidos e, em geral, os trabalhos buscam selecionar genótipos que produzam sementes com melhores características de germinação e vigor, ignorando a ação bioquímica (Reis et al., 1989).

Segundo Malavolta et al. (1997), o Mn desempenha papel fundamental na elongação celular. Em situação de deficiência, pode inibir a síntese de lipídeos ou metabólitos secundários, como o ácido giberélico e os isoprenóides. O Mn participa como catalizador em atividades enzimáticas como: malato desidrogenase, fosfatase ácida, superóxido desmutase, entre outras (Burnell, 1988).

O objetivo deste trabalho foi avaliar a influência da aplicação do Mn na folha e no solo sobre o rendimento e a qualidade das sementes das cultivares de soja Conquista e Garimpo.

\section{Material e Métodos}

O experimento foi realizado no campo de produção da Fundação de Ensino, Pesquisa e Extensão (Faepe), Ijaci, MG, latitude $21^{\circ} 10^{\prime} \mathrm{S}$, longitude $44^{\circ} 55^{\prime} \mathrm{W}$ e altitude de 805 m, em Latossolo Vermelho-Amarelo eutrófico fase cerrado, de textura média (Tabela 1). A análise química do solo foi realizada no Instituto de Química "John H. Wheelock" do Departamento de Ciência do Solo da Ufla, Lavras, MG.

Foi utilizado o delineamento em blocos ao acaso em esquema fatorial $2 \times 4 \times 3+12$, com três repetições, compreendendo duas cultivares de soja (Conquista e Garimpo), quatro doses de $\mathrm{Mn}(150,300,450$ e $600 \mathrm{~g} / \mathrm{ha}$ ), aplicadas nas folhas e três épocas de aplicação $V_{4}, V_{8}$ e $V_{10}$, respectivamente, quando a planta apresentava quatro, oito e dez trifólios com folíolos desdobrados (Fehr \& Caviness, 1977), e doze tratamentos adicionais constituídos por duas testemunhas que não receberam $\mathrm{Mn}$, seis tratamentos com parcelamento em duas vezes iguais, compreendendo 300 , 450 e $600 \mathrm{~g} / \mathrm{ha}$ aplicadas nos estádios $\mathrm{V}_{4}$ e $\mathrm{V}_{8}$, e quatro tratamentos com aplicação no solo (3,5 e 7,0 kg/ha), em ambas as cultivares. As médias dos tratamentos foram comparadas pelo teste de Scott \& Knott (1974), por não apresentarem ambigüidade nos resultados (Ferreira et al., 1999).

$\mathrm{Na}$ aplicação foliar foi utilizado o produto comercial Mangan 10, quelatizado (10\% de Mn e densidade de $1,32 \mathrm{~g} / \mathrm{mL}$ ), com auxílio de aparelho costal pressurizado com $\mathrm{CO}_{2}$ com capacidade para $20 \mathrm{~L}$, calibrado com
$45 \mathrm{lbs} / \mathrm{pol}^{2}$. Na aplicação de Mn no solo utilizou-se produto comercial na forma de sulfato de manganês ( $30 \%$ de $\mathrm{Mn})$, misturado aos adubos de plantio, cujas doses foram baseadas no valor do $\mathrm{pH}(6,8)$. Os tratamentos com aplicação foliar receberam surfactante agrícola Silwet L-77 Ag $(0,10 \%)$, para obtenção do máximo desempenho e eficiência do produto.

$\mathrm{Na}$ semeadura, no sulco de plantio, aplicou-se o superfosfato simples (100 kg/ha de $\left.\mathrm{P}_{2} \mathrm{O}_{5}\right)$ e cloreto de potássio $\left(60 \mathrm{~kg} / \mathrm{ha}\right.$ de $\left.\mathrm{K}_{2} \mathrm{O}\right)$, de acordo com a análise de solo e recomendações da Comissão de Fertilidade do Solo do Estado de Minas Gerais (1989). A adubação com ácido bórico (250 g/ha de B) e sulfato de zinco (1.250 g/ha de $\mathrm{Zn}$ ) foi feita de acordo com Raij et al. (1996). As sementes foram submetidas à inoculação de Bradyrhizobium, utilizando-se o inoculante comercial Nitral ( $250 \mathrm{~g} / 50 \mathrm{~kg}$ de sementes), e tratadas com o fungicida sistêmico Tecto $(170 \mathrm{~g} /$ $100 \mathrm{~kg}$ de sementes) e de contato Captan $(120 \mathrm{~g} / 100 \mathrm{~kg}$ de sementes), conforme Embrapa (1997).

Aos 15 dias após a emergência das plântulas realizouse o desbaste, deixando-se 17 plantas por metro linear. As parcelas foram constituídas de quatro fileiras de $5,0 \mathrm{~m}$

Tabela 1. Resultados das análises químicas do Latossolo Vermelho-Amarelo eutrófico textura média, do Município de Ijaci, MG, $1999^{(1)}$.

\begin{tabular}{lcc}
\hline Variável & \multicolumn{2}{c}{ Camada $(\mathrm{cm})$} \\
\cline { 2 - 3 } & $0-20$ & $20-40$ \\
\hline $\mathrm{pH}\left(\mathrm{H}_{2} \mathrm{O}\right)$ & 6,8 & 6,9 \\
$\mathrm{MO}(\mathrm{dag} / \mathrm{kg})$ & 3,4 & 2,1 \\
$\mathrm{P}\left(\mathrm{mg} / \mathrm{dm}^{3}\right)$ & 3,0 & 1,0 \\
$\mathrm{~S}-\mathrm{SO}_{4}\left(\mathrm{mg} / \mathrm{dm}^{3}\right)$ & 3,3 & 6,8 \\
$\mathrm{~K}\left(\mathrm{cmol}_{\mathrm{c}} / \mathrm{dm}^{3}\right)$ & 0,2 & 0,07 \\
$\mathrm{Ca}\left(\mathrm{cmol}_{\mathrm{c}} / \mathrm{dm}^{3}\right)$ & 5,2 & 3,9 \\
$\mathrm{Mg}\left(\mathrm{cmol}_{\mathrm{c}} / \mathrm{dm}^{3}\right)$ & 1,8 & 1,1 \\
$\mathrm{Al}\left(\mathrm{cmol}_{\mathrm{c}} / \mathrm{dm}^{3}\right)$ & 0,0 & 0,0 \\
$\mathrm{H}+\mathrm{Al}\left(\mathrm{cmol}_{\mathrm{c}} / \mathrm{dm}^{3}\right)$ & 2,3 & 2,3 \\
$\mathrm{SB}\left(\mathrm{cmol}_{\mathrm{c}} / \mathrm{dm}^{3}\right)$ & 7,2 & 5,1 \\
$\mathrm{~T}\left(\mathrm{cmol} / \mathrm{dm}^{3}\right)$ & 9,5 & 7,4 \\
$\mathrm{~V}\left(\mathrm{cmol} / \mathrm{dm}^{3}\right)$ & 76 & 69 \\
$\mathrm{~m}\left(\mathrm{cmol} \mathrm{cm}_{\mathrm{dm}}^{3}\right)$ & 0 & 0 \\
$\mathrm{~B}\left(\mathrm{mg} / \mathrm{dm}^{3}\right)$ & 0,4 & 0,4 \\
$\mathrm{Cu}\left(\mathrm{mg} / \mathrm{dm}^{3}\right)$ & 0,9 & 0,9 \\
$\mathrm{Fe}\left(\mathrm{mg} / \mathrm{dm}^{3}\right)$ & 38,4 & 37,8 \\
$\mathrm{Mn}\left(\mathrm{mg} / \mathrm{dm}^{3}\right)$ & 3,4 & 2,6 \\
$\mathrm{Zn}\left(\mathrm{mg} / \mathrm{dm}^{3}\right)$ & 0,1 & 0,1 \\
\hline
\end{tabular}

(1)P (resina); K (Mehlich 1); Mg e Ca extraídos com solução de KCl 1N; pH determinado em água na relação solo:água de 1:2,5; Cu, Fe, Mn e Zn extraídos por DTPA e o B por água quente. 
de comprimento, espaçadas de $0,50 \mathrm{~m}$, sendo utilizadas as duas linhas centrais como área útil, eliminando $0,50 \mathrm{~m}$ de cada lado, como bordadura, com um número total de plantas igual a 136. Após a colheita, avaliou-se o rendimento de grãos com umidade corrigida para 13\%. A análise foliar foi realizada no final do florescimento da cultura, conforme Malavolta et al. (1997).

As sementes colhidas foram limpas, trilhadas e secadas. As danificadas foram descartadas e as demais mantidas para análises posteriores.

O teste de germinação foi realizado em duas subamostras de 50 sementes por parcela, em rolo de papel, com água equivalente a 2,5 vezes o peso do substrato seco, a $30^{\circ} \mathrm{C}$. As avaliações foram efetuadas aos cinco dias após a instalação do teste (Brasil, 1992), e os resultados expressos em porcentagem média de plântulas normais por parcela.

No teste de envelhecimento artificial foram utilizadas 200 sementes por parcela, com três repetições, de modo a garantir sementes suficientes para os testes de germinação, condutividade elétrica, índice de velocidade de emergência (IVE), proteína e óleo. As sementes foram distribuídas em caixas de plástico, contendo $40 \mathrm{~mL}$ de água e mantidas a $42^{\circ} \mathrm{C}$ e umidade relativa do ar de $95 \%$, por 72 horas (Association of Official Seed Analysis, 1983).

No teste de condutividade elétrica foram preparadas três subamostras de 25 sementes por parcela. As sementes foram imersas em copos de plástico contendo $75 \mathrm{~mL}$ de água deionizada, com condutividade elétrica $\leq 2,0 \mu \mathrm{mhos} / \mathrm{cm}$, a uma temperatura de $25^{\circ} \mathrm{C}$, por 24 horas, e os resultados expressos em $\mu$ mhos $/ \mathrm{cm}$.

Na determinação do índice de velocidade de emergência foram realizadas avaliações, segundo Maguire (1962), com três e duas subamostras de 50 sementes por parcela, utilizando sementes envelhecidas e não envelhecidas artificialmente. As subamostras foram distribuídas manualmente, empregando-se régua com pregos na definição dos sulcos com $1,0 \mathrm{~m}$ de comprimento e $0,03 \mathrm{~m}$ de profundidade, sendo a distância entre sulcos de $0,08 \mathrm{~m}$. As contagens foram efetuadas diariamente, considerando como plântulas normais aquelas com cotilédones totalmente acima do solo (Feher \& Caviness, 1977).

$\mathrm{Na}$ análise do teor de óleo foram usadas amostras de 400 sementes moídas. A extração foi realizada com hexano, a quente, em extrator Soxhlet, segundo a Association of Official Agricultural Chemists (1955).

$\mathrm{O}$ teor de proteína total foi determinado pelo método Kjeldahl, e os dados expressos em porcentagem de $\mathrm{N}$ total (Association of Official Agricultural Chemists, 1955). Foram utilizadas duas repetições do teste em laboratório para cada repetição de campo, totalizando seis repetições por tratamento.

Os dados foram submetidos à análise de variância e regressão polinomial, de acordo com o procedimento proposto por Ferreira et al. (1999), utilizando-se o programa SISVAR, versão 3.01.

\section{Resultados e Discussão}

Os tratamentos com Mn proporcionaram rendimentos superiores à testemunha, com exceção do tratamento que recebeu a menor dose $(150 \mathrm{~g} / \mathrm{ha}$ de $\mathrm{Mn}$ ) no estádio $\mathrm{V}_{4}$ (Tabela 2 ). A diferença entre a produtividade média das testemunhas e a maior produtividade foi verificada nos tratamentos com parcelamento das doses de 450 e $600 \mathrm{~g} / \mathrm{ha}$ de $\mathrm{Mn}$ nos estádios $\mathrm{V}_{4}$ e $\mathrm{V}_{8}$, sendo constatado um aumento de $1.291 \mathrm{~kg} / \mathrm{ha}$ e $1.431 \mathrm{~kg} / \mathrm{ha}$, correspondente a um acréscimo de $55 \%$ e $61 \%$, respectivamente. Mascarenhas et al. (1990), Komatuda et al. (1993), Tanaka et al. (1993) e Oliveira Júnior (1996) constataram resultados semelhantes aos do presente trabalho, tanto em ensaios realizados em casa de vegetação como no campo.

Os teores foliares de $\mathrm{Mn}$ foram menores do que o nível crítico ( $<20$ ppm) nos tratamentos em que sintomas de deficiência foram observados (testemunhas, $3,5 \mathrm{~kg} / \mathrm{ha}$ de $\mathrm{Mn}$ e estádio $\mathrm{V}_{4}$ ) (Tabela 2). Esses níveis de Mn são considerados limitantes para o desenvolvimento e produção da soja (Malavolta et al., 1997). Ambas as testemunhas (Conquista e Garimpo) apresentaram sintomas de deficiência de Mn, ou seja, clorose das folhas novas e uma rede grossa das nervuras sobre fundo amarelado.

Com a aplicação do Mn no solo (pH 6,8) houve menor resposta da dose de $3,5 \mathrm{~kg} / \mathrm{ha}$, quando comparada com a maior dose $(7,0 \mathrm{~kg} / \mathrm{ha} \mathrm{de} \mathrm{Mn})$. Os tratamentos que receberam as menores doses apresentaram sintomas de deficiência desse nutriente. Tais resultados são causados pela precipitação do $\mathrm{Mn}$ no solo, em virtude do alto $\mathrm{pH}$. Nesta condição, o Mn é encontrado no solo na forma de óxidos insolúveis e, conseqüentemente, apresentam baixa disponibilidade do elemento às plantas (Malavolta, 1986; Sparrow \& Uren, 1987).

As sementes submetidas ao teste de germinação, sem envelhecimento, apresentaram valores entre $91 \%$ e $96 \%$ e $89 \%$ e $93 \%$ em relação às cultivares Conquista e Garimpo, respectivamente (Tabela 3).

Quanto ao vigor, avaliado pela emergência de plântulas no campo, os tratamentos antes do enve- 
Tabela 2. Rendimento de grãos, produção relativa à testemunha e teores foliares de manganês, obtidos no ensaio de adubação com manganês, em duas cultivares de soja ano agrícola 1997/98. Ufla, Ijaci, MG, 1999(1).

\begin{tabular}{|c|c|c|c|c|c|c|c|}
\hline \multirow{2}{*}{$\begin{array}{l}\text { Tratamento }^{(2)} \\
(\mathrm{Mn} / \mathrm{ha})\end{array}$} & \multicolumn{3}{|c|}{ Grãos (kg/ha) } & \multirow{2}{*}{$\begin{array}{c}\text { Produção relativa } \\
(\%)\end{array}$} & \multicolumn{3}{|c|}{ Mn foliar (mg/kg) } \\
\hline & Conquista & Garimpo & Média & & Conquista & Garimpo & Média \\
\hline Testemunha & 2.644 & 2.032 & $2.338 \mathrm{~d}$ & 100 & 6,85 & 7,87 & $7,36 \mathrm{~g}$ \\
\hline 3,5 kg (sulco) & 3.107 & 2.890 & $2.999 \mathrm{c}$ & 128 & 12,48 & 13,88 & $13,18 \mathrm{f}$ \\
\hline $7,0 \mathrm{~kg}$ (sulco) & 3.504 & 3.161 & $3.332 b$ & 143 & 25,18 & 27,67 & $26,42 d$ \\
\hline $150 \mathrm{~g}\left(\mathrm{~V}_{4}\right)$ & 2.675 & 2.476 & $2.575 \mathrm{~d}$ & 110 & 14,31 & 16,17 & $15,24 \mathrm{f}$ \\
\hline $300 \mathrm{~g}\left(\mathrm{~V}_{4}\right)$ & 2.777 & 2.787 & $2.782 \mathrm{c}$ & 119 & 14,38 & 15,81 & $15,10 \mathrm{f}$ \\
\hline $450 \mathrm{~g}\left(\mathrm{~V}_{4}\right)$ & 3.286 & 3.090 & $3.188 \mathrm{~b}$ & 136 & 14,78 & 16,47 & $15,62 \mathrm{f}$ \\
\hline $600 \mathrm{~g}\left(\mathrm{~V}_{4}\right)$ & 2.935 & 2.903 & $2.919 \mathrm{c}$ & 125 & 15,68 & 13,28 & $14,48 \mathrm{f}$ \\
\hline $150 \mathrm{~g}\left(\mathrm{~V}_{8}\right)$ & 3.393 & 2.896 & $3.144 \mathrm{~b}$ & 134 & 21,57 & 18,47 & $20,02 \mathrm{e}$ \\
\hline $300 \mathrm{~g}\left(\mathrm{~V}_{8}\right)$ & 3.425 & 3.143 & $3.284 \mathrm{~b}$ & 140 & 21,67 & 21,37 & $21,52 \mathrm{e}$ \\
\hline $450 \mathrm{~g}\left(\mathrm{~V}_{8}\right)$ & 3.506 & 3.265 & $3.385 \mathrm{~b}$ & 145 & 22,70 & 20,97 & $21,83 \mathrm{e}$ \\
\hline $600 \mathrm{~g}\left(\mathrm{~V}_{8}\right)$ & 3.376 & 2.950 & $3.163 \mathrm{~b}$ & 135 & 24,86 & 20,67 & $22,77 \mathrm{e}$ \\
\hline $150 \mathrm{~g}\left(\mathrm{~V}_{10}\right)$ & 2.973 & 3.097 & $3.035 \mathrm{c}$ & 130 & 29,92 & 36,77 & $33,34 \mathrm{c}$ \\
\hline $300 \mathrm{~g}\left(\mathrm{~V}_{10}\right)$ & 3.340 & 3.117 & $3.289 \mathrm{~b}$ & 141 & 42,78 & 39,44 & $41,11 \mathrm{~b}$ \\
\hline $450 \mathrm{~g}\left(\mathrm{~V}_{10}\right)$ & 3.346 & 3.144 & $3.245 \mathrm{~b}$ & 139 & 38,84 & 46,03 & $42,44 \mathrm{~b}$ \\
\hline $600 \mathrm{~g}\left(\mathrm{~V}_{10}\right)$ & 3.560 & 3.064 & $3.312 b$ & 142 & 60,00 & 74,58 & $67,29 a$ \\
\hline $150+150 \mathrm{~g}\left(\mathrm{~V}_{4} \mathrm{e} \mathrm{V}_{8}\right)$ & 3.751 & 3.153 & $3.452 b$ & 148 & 23,58 & 23,88 & $23,73 \mathrm{e}$ \\
\hline $225+225 \mathrm{~g}\left(\mathrm{~V}_{4} \mathrm{e} \mathrm{V}_{8}\right)$ & 3.842 & 3.417 & $3.629 \mathrm{a}$ & 155 & 24,24 & 26,87 & $25,55 \mathrm{~d}$ \\
\hline $300+300 \mathrm{~g}\left(\mathrm{~V}_{4} \mathrm{e} \mathrm{V}_{8}\right)$ & 4.063 & 3.476 & $3.769 \mathrm{a}$ & 161 & 26,77 & 26,27 & $26,52 \mathrm{~d}$ \\
\hline Média & 3.306 & 3.003 & 3.155 & 135 & 24,48 & 25,91 & 25,20 \\
\hline
\end{tabular}

${ }^{(1)}$ Médias seguidas pela mesma letra, nas colunas, não diferem entre si a $1 \%$ de probabilidade pelo teste de Scott \& Knott (1974). ${ }^{(2)} \mathrm{V}_{4}$ : planta com quatro trifólios; $\mathrm{V}_{8}$ : planta com oito trifólios; $\mathrm{V}_{10}$ : planta com dez trifólios.

Tabela 3. Germinação de sementes, emergência de plântulas no campo e índice de velocidade de emergência de duas cultivares de soja, antes e após o envelhecimento artificial, em razão de tratamentos aplicados no ano agrícola 1997/98. Ufla, Lavras, $\mathrm{MG}^{(1)}$.

\begin{tabular}{|c|c|c|c|c|c|c|c|c|c|c|c|c|}
\hline \multirow{3}{*}{$\begin{array}{l}\text { Tratamento } \\
(\mathrm{Mn} / \mathrm{ha})\end{array}$} & \multicolumn{4}{|c|}{ Germinação (\%) } & \multicolumn{4}{|c|}{ Emergência (\%) } & \multicolumn{4}{|c|}{ Índice de velocidade de emergência } \\
\hline & \multicolumn{2}{|c|}{ Antes } & \multicolumn{2}{|c|}{ Após } & \multicolumn{2}{|c|}{ Antes } & \multicolumn{2}{|c|}{ Após } & \multicolumn{2}{|c|}{ Antes } & \multicolumn{2}{|c|}{ Após } \\
\hline & Conquista & Garimpo & Conquista & Garimpo & Conquista & Garimpo & Conquista & Garimpo & Conquista & Garimpo & Conquista & Garimpo \\
\hline Testemunha & 94 & 89 & $90 \mathrm{a}$ & $78 \mathrm{c}$ & 97 & 90 & $76 b$ & $51 b$ & $6,6 a$ & $6,4 \mathrm{a}$ & $5,9 b$ & $4,2 \mathrm{c}$ \\
\hline $3,5 \mathrm{~kg}$ (sulco) & 92 & 90 & $88 b$ & $81 b$ & 96 & 95 & $87 \mathrm{a}$ & $72 \mathrm{a}$ & $6,5 \mathrm{a}$ & $6,7 \mathrm{a}$ & $7,0 \mathrm{a}$ & $5,9 \mathrm{~b}$ \\
\hline $7,0 \mathrm{~kg}$ (sulco) & 93 & 91 & $88 \mathrm{~b}$ & $86 a$ & 97 & 96 & $90 \mathrm{a}$ & $81 \mathrm{a}$ & $6,4 a$ & $6,6 a$ & $7,5 \mathrm{a}$ & $6,9 a$ \\
\hline $150 \mathrm{~g}\left(\mathrm{~V}_{4}\right)$ & 95 & 90 & $90 \mathrm{a}$ & $84 a$ & 95 & 95 & $84 a$ & $68 \mathrm{a}$ & $6,4 a$ & $6,8 \mathrm{a}$ & $7,3 \mathrm{a}$ & $5,5 b$ \\
\hline $300 \mathrm{~g}\left(\mathrm{~V}_{4}\right)$ & 94 & 89 & $89 a$ & $83 a$ & 96 & 93 & $88 \mathrm{a}$ & $77 \mathrm{a}$ & $6,5 \mathrm{a}$ & $6,5 \mathrm{a}$ & $7,8 \mathrm{a}$ & $6,3 \mathrm{a}$ \\
\hline $450 \mathrm{~g}\left(\mathrm{~V}_{4}\right)$ & 92 & 90 & $88 b$ & $84 a$ & 98 & 92 & $87 \mathrm{a}$ & $79 a$ & $6,4 a$ & $6,3 a$ & $7,7 \mathrm{a}$ & $6,8 \mathrm{a}$ \\
\hline $600 \mathrm{~g}\left(\mathrm{~V}_{4}\right)$ & 92 & 92 & $86 b$ & $85 a$ & 96 & 91 & $87 a$ & $76 a$ & $6,3 a$ & $6,4 a$ & $7,2 \mathrm{a}$ & $6,6 a$ \\
\hline $150 \mathrm{~g}\left(\mathrm{~V}_{8}\right)$ & 91 & 90 & $86 b$ & $84 a$ & 97 & 95 & $85 a$ & $77 \mathrm{a}$ & $6,4 a$ & $6,8 \mathrm{a}$ & $6,7 b$ & $6,7 \mathrm{a}$ \\
\hline $300 \mathrm{~g}\left(\mathrm{~V}_{8}\right)$ & 92 & 91 & $86 b$ & $86 a$ & 98 & 95 & $91 \mathrm{a}$ & $78 \mathrm{a}$ & $6,6 a$ & $6,6 \mathrm{a}$ & $7,8 \mathrm{a}$ & $6,7 \mathrm{a}$ \\
\hline $450 \mathrm{~g}\left(\mathrm{~V}_{8}\right)$ & 93 & 91 & $87 b$ & $85 \mathrm{a}$ & 95 & 96 & $88 \mathrm{a}$ & $86 a$ & $6,3 a$ & $6,9 a$ & $7,1 \mathrm{a}$ & $7,4 a$ \\
\hline $600 \mathrm{~g}\left(\mathrm{~V}_{8}\right)$ & 96 & 90 & $90 \mathrm{a}$ & $85 a$ & 98 & 96 & $90 \mathrm{a}$ & $81 \mathrm{a}$ & $6,6 a$ & $6,8 \mathrm{a}$ & $7,4 a$ & $6,9 \mathrm{a}$ \\
\hline $150 \mathrm{~g}\left(\mathrm{~V}_{10}\right)$ & 95 & 91 & $88 b$ & $85 a$ & 95 & 96 & $85 a$ & $82 \mathrm{a}$ & $6,3 a$ & $6,9 a$ & $7,2 \mathrm{a}$ & $7,1 \mathrm{a}$ \\
\hline $300 \mathrm{~g}\left(\mathrm{~V}_{10}\right)$ & 92 & 91 & $86 b$ & $84 a$ & 96 & 95 & $88 \mathrm{a}$ & $80 \mathrm{a}$ & $6,2 \mathrm{a}$ & $6,8 \mathrm{a}$ & $7,2 \mathrm{a}$ & $6,8 \mathrm{a}$ \\
\hline $450 \mathrm{~g}\left(\mathrm{~V}_{10}\right)$ & 91 & 92 & $85 b$ & $85 \mathrm{a}$ & 96 & 95 & $90 \mathrm{a}$ & $78 \mathrm{a}$ & $6,4 a$ & $6,7 \mathrm{a}$ & $7,8 \mathrm{a}$ & $6,5 \mathrm{a}$ \\
\hline $600 \mathrm{~g}\left(\mathrm{~V}_{10}\right)$ & 94 & 92 & $88 b$ & $87 \mathrm{a}$ & 95 & 96 & $88 \mathrm{a}$ & $80 \mathrm{a}$ & $6,3 a$ & $6,8 \mathrm{a}$ & $7,4 \mathrm{a}$ & $6,8 \mathrm{a}$ \\
\hline $150+150 \mathrm{~g}\left(\mathrm{~V}_{4} \mathrm{e} \mathrm{V}_{8}\right)$ & 92 & 91 & $90 \mathrm{a}$ & $86 a$ & 97 & 96 & $88 \mathrm{a}$ & $76 a$ & $6,5 \mathrm{a}$ & $6,7 \mathrm{a}$ & $7,5 \mathrm{a}$ & $6,4 \mathrm{a}$ \\
\hline $225+225 \mathrm{~g}\left(\mathrm{~V}_{4} \mathrm{e} \mathrm{V}_{8}\right)$ & 92 & 91 & $90 \mathrm{a}$ & $87 \mathrm{a}$ & 96 & 94 & $88 \mathrm{a}$ & $77 \mathrm{a}$ & $6,5 \mathrm{a}$ & $6,6 a$ & $7,5 \mathrm{a}$ & $7,0 \mathrm{a}$ \\
\hline $300+300 \mathrm{~g}\left(\mathrm{~V}_{4} \mathrm{e} \mathrm{V}_{8}\right)$ & 95 & 93 & $84 a$ & $88 \mathrm{a}$ & 96 & 95 & $91 \mathrm{a}$ & $83 \mathrm{a}$ & $6,6 \mathrm{a}$ & $6,9 \mathrm{a}$ & $7,6 a$ & $6,7 \mathrm{a}$ \\
\hline Médias & 93 & 91 & 88 & 85 & 96 & 95 & 87 & 77 & 6,4 & 6,7 & 7,3 & 6,5 \\
\hline
\end{tabular}

${ }^{(1)}$ Médias seguidas pela mesma letra, nas colunas, não diferem entre si a 5\% de probabilidade pelo teste de Scott \& Knott (1974); os coeficientes de variação em relação à germinação antes e após o envelhecimento artificial foram de 2,60\% e 2,34\%, respectivamente; em relação à emergência antes e após o envelhecimento artificial foram de $2,60 \%$ e $6,44 \%$, respectivamente, e, em relação ao índice de velocidade de emergência antes e após o envelhecimento artificial foram de $3,57 \%$ e $7,84 \%$, respectivamente. ${ }^{(2)} \mathrm{V}_{4}, \mathrm{~V}_{8}$ e $\mathrm{V}_{10}$ referem-se à época de aplicação do tratamento quando as plantas estavam com quatro, oito e dez trifólios, respectivamente. 
lhecimento artificial apresentaram emergência acima de $90 \%$ e $95 \%$ nas cultivares Garimpo e Conquista, respectivamente (Tabela 3). Após a realização do envelhecimento houve uma diminuição média na emergência de $10 \%$ e $23 \%$ nas cultivares Conquista e Garimpo, respectivamente. Tais valores indicam menor vigor das sementes em virtude do envelhecimento, sendo observada nas sementes da cultivar Garimpo maior redução de vigor em relação às testemunhas de ambas as cultivares, podendo-se observar diferença de $43 \%$ na emergência da cultivar Garimpo, assim como queda de $22 \%$ da cultivar Conquista. Esse fato corrobora a análise do efeito do Mn no vigor das sementes, visto que os tratamentos que o receberam apresentaram valores acima dos valores das suas testemunhas, em ambas as cultivares.

Segundo Filgueiras (1981), Nakagawa et al. (1984) e Krzyzanowski et al. (1991), sementes com baixo vigor, mesmo com alta porcentagem de germinação, podem resultar em prejuízos aos agricultores quando submetidas a condições desfavoráveis de campo, principalmente pelo estabelecimento inadequado de estande.

A condutividade elétrica da cultivar Garimpo variou entre 51,82 e 91,40 $\mu \mathrm{mhos} / \mathrm{cm} / \mathrm{g}$ (Tabela 4). Esses valores permitiram separar sementes da cultivar Garimpo com níveis de alto e baixo vigor, como constatado por Costa (1986) e Bhering et al. (1991). Esses autores verificaram também associação de sementes de alto vigor com valores de condutividade elétrica abaixo de $70 \mu \mathrm{mhos} / \mathrm{cm} / \mathrm{g}$, e de sementes de baixo vigor com valores acima de $80 \mu \mathrm{mhos} / \mathrm{cm} / \mathrm{g}$.

De acordo com Malavolta et al. (1997), o Mn é requerido para a atividade da dismutase de peróxido, a qual protege a célula de efeitos deletérios de radicais livres. Assim, é provável ocorrer, em situação de deficiência de Mn, mudanças nos ácidos graxos insaturados, pela ação desses radicais livres, resultando na desestruturação da membrana celular, o que explica os altos valores de condutividade encontrados especialmente em sementes da cultivar Garimpo (Carvalho, 1994).

As sementes, quando submetidas ao teste do índice de velocidade de emergência antes do envelhecimento, não apresentaram diferença estatística entre os tratamentos, ao contrário do teste feito após o envelhecimento (Tabela 3). Sementes de alto vigor originaram plântulas com melhores índices, revelando uma relação direta entre a velocidade de emergência das plântulas e o vigor das sementes. A cultivar Garimpo apresentou redução no índice acima do verificado na cultivar Conquista, quando comparados os tratamentos testemunha das duas cultivares, antes e depois do envelhecimento. Foi observada queda de 6,4 para 4,2 pontos no índice da cultivar Garimpo, e de 6,6 para 5,9 pontos no da cultivar Conquista. Constataram-se, ainda, índices abaixo de 6,0 pontos nos tratamentos com dose baixa de Mn aplicada no solo ou na folha, no estádio $V_{4}$, na cultivar Garimpo.

Esses valores estão de acordo com os encontrados no teste de condutividade elétrica, o que revela uma relação entre alto valor de condutividade elétrica e baixo vigor das sementes. $O$ teste de velocidade de emergência distinguiu a qualidade das sementes entre os tratamentos dentro das cultivares, tendência também verificada no teste de germinação em rolo de papel.

Os teores mais baixos de proteína foram detectados nos tratamentos testemunha com $34,78 \%$ e $36,22 \%$, nas cultivares Conquista e Garimpo, respectivamente (Tabela 4). Os maiores teores de proteína foram encontrados nos tratamentos que receberam as maiores doses de Mn, independentemente da cultivar, revelando uma superioridade média de 4,95\% quando comparados com as testemunhas. A cultivar Garimpo apresentou sementes com teores de proteína em média 2,61\% superiores aos da cultivar Conquista. Alem disso, foram constatados valores, em média, 3,68\% superiores nos tratamentos que receberam Mn, tanto no solo como nas folhas, quando comparados com a testemunha.

Constataram-se teores de óleo acima de 20,0\% nos tratamentos que receberam $\mathrm{Mn}$, em ambas as cultivares (Tabela 4). Houve uma diferença de 2,37\% e 2,57\%, em média, nas cultivares Conquista e Garimpo, respectivamente, nos tratamentos que receberam $\mathrm{Mn}$, quando comparadas com as testemunhas. Wilson et al. (1982) também verificaram alteração no teor de óleo em condições de baixos níveis de $\mathrm{Mn}$ nas folhas $(<10 \mathrm{ppm})$, sendo observada ainda a importância das condições climáticas e localização geográfica como fatores que influenciam os níveis de ácidos graxos nos teores de óleo em soja. 
Tabela 4. Condutividade elétrica ( $\mu \mathrm{mhos} / \mathrm{cm} / \mathrm{g})$, teor de proteína e teor de óleo, de sementes de duas cultivares de soja em razão dos tratamentos, no ano agrícola 1997/98. Ufla, Lavras, MG, 1999(1).

\begin{tabular}{|c|c|c|c|c|c|c|}
\hline \multirow[t]{2}{*}{$\begin{array}{l}\text { Tratamento }^{(2)} \\
(\mathrm{Mn} / \mathrm{ha})\end{array}$} & \multicolumn{2}{|c|}{$\begin{array}{c}\text { Condutividade elétrica } \\
(\mu \mathrm{mhos} / \mathrm{cm} / \mathrm{g})\end{array}$} & \multicolumn{2}{|c|}{$\begin{array}{c}\text { Proteína } \\
(\%)\end{array}$} & \multicolumn{2}{|c|}{$\begin{array}{c}\text { Óleo } \\
(\%)\end{array}$} \\
\hline & Conquista & Garimpo & Conquista & Garimpo & Conquista & Garimpo \\
\hline Testemunha & 71,63 & $91,40 \mathrm{a}$ & $34,78 \mathrm{~d}$ & $36,22 \mathrm{c}$ & $19,00 \mathrm{~d}$ & $18,17 \mathrm{c}$ \\
\hline $3,5 \mathrm{~kg}$ (sulco) & 66,33 & $60,50 \mathrm{c}$ & $36,73 \mathrm{c}$ & $39,12 b$ & $21,48 b$ & $21,38 \mathrm{a}$ \\
\hline $7,0 \mathrm{~kg}$ (sulco) & 56,25 & $51,82 \mathrm{c}$ & $36,08 \mathrm{c}$ & $38,92 b$ & $22,63 \mathrm{a}$ & $22,20 \mathrm{a}$ \\
\hline $150 \mathrm{~g}\left(\mathrm{~V}_{4}\right)$ & 60,40 & $69,19 b$ & $35,68 \mathrm{~d}$ & $39,25 b$ & $20,22 \mathrm{c}$ & $20,88 b$ \\
\hline $300 \mathrm{~g}\left(\mathrm{~V}_{4}\right)$ & 61,39 & $69,34 b$ & $37,65 b$ & $39,68 b$ & $21,23 b$ & $20,18 b$ \\
\hline $450 \mathrm{~g}\left(\mathrm{~V}_{4}\right)$ & 57,81 & $67,21 b$ & $38,98 \mathrm{a}$ & $40,13 \mathrm{a}$ & $21,30 \mathrm{~b}$ & $21,48 \mathrm{a}$ \\
\hline $600 \mathrm{~g}\left(\mathrm{~V}_{4}\right)$ & 57,16 & $66,88 \mathrm{~b}$ & $38,48 \mathrm{a}$ & $40,88 \mathrm{a}$ & $21,55 \mathrm{~b}$ & $20,80 \mathrm{~b}$ \\
\hline $150 \mathrm{~g}\left(\mathrm{~V}_{8}\right)$ & 64,24 & $65,72 b$ & $36,63 \mathrm{c}$ & $39,55 \mathrm{~b}$ & $20,97 b$ & $20,70 b$ \\
\hline $300 \mathrm{~g}\left(\mathrm{~V}_{8}\right)$ & 62,35 & $70,07 \mathrm{~b}$ & $37,52 b$ & $40,30 \mathrm{a}$ & $21,25 b$ & $20,72 b$ \\
\hline $450 \mathrm{~g}\left(\mathrm{~V}_{8}\right)$ & 65,63 & $56,89 \mathrm{c}$ & $37,13 \mathrm{c}$ & $40,85 \mathrm{a}$ & $20,88 b$ & $20,90 \mathrm{~b}$ \\
\hline $600 \mathrm{~g}\left(\mathrm{~V}_{8}\right)$ & 64,41 & $58,75 \mathrm{c}$ & $38,98 \mathrm{a}$ & $41,07 \mathrm{a}$ & $21,85 \mathrm{a}$ & $20,97 b$ \\
\hline $150 \mathrm{~g}\left(\mathrm{~V}_{10}\right)$ & 63,31 & $56,80 \mathrm{c}$ & $37,48 b$ & $38,48 b$ & $21,03 b$ & $20,23 b$ \\
\hline $300 \mathrm{~g}\left(\mathrm{~V}_{10}\right)$ & 62,51 & $65,65 b$ & $37,53 b$ & $39,78 b$ & $21,20 \mathrm{~b}$ & $20,80 \mathrm{~b}$ \\
\hline $450 \mathrm{~g}\left(\mathrm{~V}_{10}\right)$ & 66,77 & $59,67 \mathrm{c}$ & $37,63 b$ & $40,38 \mathrm{a}$ & $22,33 \mathrm{a}$ & $21,08 b$ \\
\hline $600 \mathrm{~g}\left(\mathrm{~V}_{10}\right)$ & 60,67 & $65,86 \mathrm{~b}$ & $38,38 \mathrm{a}$ & $41,92 \mathrm{a}$ & $22,63 a$ & $20,13 b$ \\
\hline $150+150 \mathrm{~g}\left(\mathrm{~V}_{4} \mathrm{e} \mathrm{V}_{8}\right)$ & 60,50 & $66,98 b$ & $36,45 c$ & $38,90 \mathrm{~b}$ & $21,28 b$ & $20,90 b$ \\
\hline $225+225 \mathrm{~g}\left(\mathrm{~V}_{4} \mathrm{e} \mathrm{V}_{8}\right)$ & 55,78 & $56,62 \mathrm{c}$ & $36,98 \mathrm{c}$ & $40,87 \mathrm{a}$ & $21,72 b$ & $20,60 b$ \\
\hline $300+300 \mathrm{~g}\left(\mathrm{~V}_{4}\right.$ e $\left.V_{8}\right)$ & 54,71 & $61,45 \mathrm{c}$ & $38,15 \mathrm{a}$ & $41,83 \mathrm{a}$ & $22,10 \mathrm{a}$ & $21,15 b$ \\
\hline Médias & 61,77 & 64,43 & 37,29 & 39,90 & 21,37 & 20,74 \\
\hline
\end{tabular}

(1) Médias seguidas pela mesma letra, na coluna, não diferem entre si a 5\% de probabilidade pelo teste de Scott \& Knott (1974); os coeficientes de variação em relação à condutividade elétrica, teor de proteína e teor de óleo foram $10,07 \%, 1,91 \%$ e $2,36 \%$, respectivamente. (2) $\mathrm{V}_{4}, \mathrm{~V}_{8}$ e $\mathrm{V}_{10}$ referem-se à época de aplicação do tratamento quando as plantas estavam com quatro, oito e dez trifólios, respectivamente.

Cabe ressaltar a importância de teores adequados de proteína e óleo nas sementes, pois esses elementos são responsáveis pela determinação da qualidade e quantidade dos produtos finais, como o farelo e o óleo de soja (Hurburgh Junior et al., 1990). Tais resultados concordam com os relatados por Tanaka \& Mascarenhas (1992), que sugerem uma correlação positiva entre a produtividade de grãos e o teor de óleo, a qual é atribuída aos teores de Mn nas folhas de soja.

Existem evidências de que o Mn tem efeito indireto na redução do nitrato. A atividade da redutase do nitrato é dependente de substrato produzido fotossinteticamente pela geração de agentes redutores em folhas verdes. Como a fotossíntese é reduzida pela deficiência de Mn, é possível que a fonte do agente redutor em plantas deficientes em Mn seja reduzida (Heenan \& Campbell, 1980). Assim, podese sugerir que o Mn desempenha papel indireto na geração de esqueletos de $\mathrm{C}$ e $\mathrm{N}$ para a síntese de proteínas.

\section{Conclusões}

1. A aplicação do Mn, independentemente da cultivar e da forma de aplicação, aumenta a produtividade de grãos, a germinação, a condutividade elétrica, o índice de velocidade de emergência e os teores de proteína e óleo da soja.

2. Na correção da deficiência de Mn na soja, a aplicação nas folhas é mais eficiente do que a aplicação no solo.

\section{Referências}

ASSOCIATION OF OFFICIAL AGRICULTURAL CHEMISTS (Arlington, Estados Unidos). Official methods of analysis. 8. ed. Washington, 1955. p. 30.

ASSOCIATION OF OFFICIAL SEED ANALYSTS (Las Cruces, Estados Unidos). Seed vigor testing handbook. East Lansing, 1983. 88 p. (Contribution, 32). 
BHERING, M. C.; REIS, M. S.; SEDIYAMA, C. S.; SEDIYAMA, T.; ANDRADE, M. A. S. Influência de épocas de plantio sobre a qualidade fisiológica de sementes de soja [Glycine $\max$ (L.) Merrill]. Revista Ceres, Viçosa, MG, v. 38, n. 219, p. 409-421, set./out. 1991.

BRASIL. Ministério da Agricultura e Reforma Agrária. Secretaria Nacional de Defesa Sanitária. Departamento Nacional de Defesa Vegetal. Regras para análise de sementes. Brasília, 1992. 365 p.

BURNELL, J. N. The biochemistry of manganese in plants. In: GRAHAM, R. D.; HANNAM, R. J.; UREN, N. C. (Ed.). Manganese in soils and plant. Dordrecht: Kluwer Academic, 1988. p. 125-137.

CARVALHO, N. M. de. O conceito de vigor em sementes. In: VIEIRA, R. D.; CARVALHO, N. M. (Ed.). Testes de vigor em sementes. Jaboticabal: Funep, 1994. p. 1-30.

COMISSÃO DE FERTILIDADE DO SOLO DO ESTADO DE MINAS GERAIS (Lavras, MG). Recomendações para uso de corretivos e fertilizantes em Minas Gerais: $4^{a}$ aproximação. Lavras, 1989. 159 p.

COSTA, A. F. S. Avaliação da qualidade fisiológica das sementes de genótipos de soja [Glycine max (L.) Merrill], produzidas em cinco localidades do Estado de Minas Gerais. 1986. 110 f. Dissertação (Mestrado em Fitotecnia) - Universidade Federal de Viçosa, Viçosa, 1986.

EMBRAPA. Centro Nacional de Pesquisa de Soja (Londrina, PR). Recomendações técnicas para a cultura da soja na região Central do Brasil: 1997/1998. Londrina, 1997. 171 p. (Documentos, 106).

FEHR, W. R.; CAVINESS, C. E. Stages of soybean development. Ames: Iowa State University, 1977. 12 p. (Special Report, 80).

FERREIRA, F. D.; MUNIZ, J. A.; AQUINO, L. H. Comparações múltiplas em experimentos com grande número de tratamentos: utilização do teste de Scott-Knott. Ciência e Agrotecnologia, Lavras, v. 23, n. 3, p. 747-752, jul./set. 1999.

FILGUEIRAS, T. S. Seed vigor and productivity. Pesquisa Agropecuária Brasileira, Brasília, v. 16, n. 6, p. 851-854, jun. 1981.

GUODONG, Z.; JINLING, W. Periodical variation and geographical distribution of protein and oil content soybean varieties in Heilongjiang province, China. Soybean Genetics Newsletter, Ames, v. 16, p. 41-42, 1989.
HEENAN, D. P.; CAMPBELL, L. C. Soybean nitrate reductase activity influenced by manganese nutrition. Plant and Cell Physiology, Kyoto, v. 21, n. 4, p. 731-736, June 1980.

HURBURGH JUNIOR, C. R.; BRUMM, T. J.; GUINN, J. M.; HARTWIG, R. A. Protein and oil patterns in U. S. and world soybean markets. Journal of the American Oil Chemist's Society, Champaign, v. 67, n. 12, p. 887-1044, 1990.

KOMATUDA, C. R. N.; SEDIYAMA, C. S.; NOVAIS, R. F.; MONNERAT, P. H.; NEVES, J. C. C. Comportamento de cultivares de soja sob deficiência ou excesso de manganês em solução nutritiva. Revista Brasileira de Ciência do Solo, Campinas, v. 17, p. 217-221, 1993.

KRZYZANOWSKI, F. C.; FRANÇA NETO, J. B.; HENNING, A. A. Relatos dos testes de vigor disponíveis para as grandes culturas. Informativo ABRATES, Brasília, v. 1, n. 2, p. 15-50, mar. 1991.

MAGUIRE, J. D. Speed of germination-aid seedling emergence and vigor. Crop Science, Madison, v. 2, n. 2, p. 176-177, Mar./Apr. 1962.

MALAVOLTA, E. Micronutrientes na adubação. Piracicaba: Nutriplant Indústria e Comércio, 1986. 70 p.

MALAVOLTA, E.; VITTI, G. C.; OLIVEIRA, S. A. de. Avaliação do estado nutricional das plantas: princípios e aplicações. 2. ed. Piracicaba: Potafos, 1997. 319 p.

MASCARENHAS, H. A. A.; MIRANDA, M. A. C.; TANAKA, R. T.; FALIVENE, S. M. P.; DECHEM, A. R. Comportamento de cultivares de soja em solução nutritiva contendo diferentes níveis de manganês. Pesquisa Agropecuária Brasileira, Brasília, v. 25, n. 4, p. 609-615, abr. 1990.

MASCARENHAS, H. A. A.; TANAKA, R. T.; GALLO, P. B.; PEREIRA, J. C. V. N. A.; AMBROSANO, G. M. B.; CARMELLO, Q. A. C. Efeito da calagem sobre a produtividade de grãos, óleo e proteína em cultivares precoces de soja. Scientia Agricola, Piracicaba, v. 53, n. 1, p. 164-171, jan./abr. 1996.

NAKAGAWA, J.; ROSOLEM, C. A.; MACHADO, J. R. Desempenho de sementes de soja originárias de culturas estabelecidas em diferentes épocas. Revista Brasileira de Sementes, Brasília, v. 6, n. 3, p. 61-76, 1984.

OLIVEIRA JÚNIOR, J. A. Efeitos do manganês sobre a soja em solução nutritiva e em solo do cerrado do triângulo mineiro. 1996. 69 f. Dissertação (Mestrado em Energia Nuclear na Agricultura) - Centro de Energia Nuclear na Agricultura, Universidade de São Paulo, Piracicaba, 1996. 
RAIJ, B. van; CANTARELLA, H.; QUAGGIO, J. A.; FURLANI, A. M. C. (Ed.). Recomendações de adubação e calagem para o Estado de São Paulo. 2. ed. Campinas: Instituto Agronômico, 1996. 285 p.

REIS, W. J. P.; ROCHA, V. S.; REZENDE, S. T. Correlação entre a evolução de n-hexanal e aldeídos totais e a germinação e vigor de sementes de soja. Revista Ceres, Viçosa, MG, v. 36, n. 203, p. 27-37, jan./fev. 1989.

SCOTT, A. J.; KNOTT, M. A cluster analysis method for grouping means in the analysis of variance. Biometrics, Washington, v. 30, p. 507-512, Sept. 1974.

SPARROW, L. A.; UREN, N. C. Oxidation and reduction of $\mathrm{Mn}$ in acidic soils: effect of temperature and soil $\mathrm{pH}$.
Soil Biology and Biochemistry, Oxford, v. 19, n. 2, p. 143-148, 1987.

TANAKA, R. T.; MASCARENHAS, H. A. A. Soja: nutrição, correção do solo e adubação. Campinas: Fundação Cargill, 1992. 60 p. (Boletim Técnico, 7).

TANAKA, R. T.; MASCARENHAS, H. A. A.; BULISANI, E. A. Manganese deficiency in soybeans induced by excess lime. Better Crops International, Norcross, v. 9, n. 2, p. 7, Dec. 1993.

WILSON, D. O.; BOSWELL, F. C.; OHKI, K.; PARKER, M. B.; SHUMAN, L. M.; JELLUM, M. D. Changes in soybean seed oil and protein as influenced by manganese nutrition. Crop Science, Madison, v. 22, n. 5, p. 948-952, Sept./Oct. 1982. 